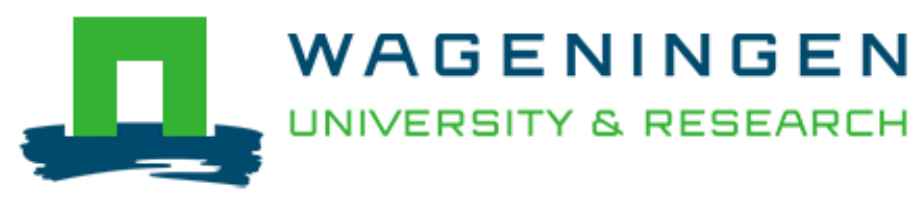

Fair gain allocation in eco-efficient vendor-managed inventory cooperation

Stellingwerf, H. M., Kanellopoulos, A., Cruijssen, F. C. A. M., \& Bloemhof, J. M.

This is a "Post-Print" accepted manuscript, which has been Published in "Journal of Cleaner Production"

This version is distributed under a non-commercial no derivatives Creative Commons (ㄷ) (1) @) ( 9 (CC-BY-NC-ND) user license, which permits use, distribution, and reproduction in any medium, provided the original work is properly cited and not used for commercial purposes. Further, the restriction applies that if you remix, transform, or build upon the material, you may not distribute the modified material.

Please cite this publication as follows:

Stellingwerf, H. M., Kanellopoulos, A., Cruijssen, F. C. A. M., \& Bloemhof, J. M. (2019). Fair gain allocation in eco-efficient vendor-managed inventory cooperation. Journal of Cleaner Production, 231, 746-755.

https://doi.org/10.1016/j.jclepro.2019.05.232

You can download the published version at:

https://doi.org/10.1016/j.jclepro.2019.05.232 


\title{
Fair gain allocation in eco-efficient vendor-managed inventory cooperation
}

\author{
H.M. Stellingwerf ${ }^{a, 1}$, A. Kanellopoulos ${ }^{a}$, F.C.A.M.Cruijssen ${ }^{b}$, J.M. Bloemhof ${ }^{a}$ \\ ${ }^{a}$ Wageningen University, Hollandseweg 1, $6706 \mathrm{KN}$ Wageningen, The Netherlands \\ ${ }^{b}$ ArgusI, Ceresstraat 15G, 4811 CA, Breda, The Netherlands
}

\begin{abstract}
Transportation is not always organised efficiently, which causes unnecessary costs and $\mathrm{CO}_{2}$ emissions. Vendor-managed inventory (VMI) has been suggested as a form of cooperation that can reduce economic and environmental impacts of transportation and consequently improve eco-efficiency of the supply chain. Establishing viable forms of VMI cooperation requires a fair distribution of the cooperation's economic benefits. Cooperative game theory (CGT) research is used to fairly allocate both benefits and costs. However, the environmental contribution of partners has often been ignored in the benefit allocation. In this study, the Shapley value (a commonly used CGT method) is used to share the monetary gains in a way that reflects the partners' contributions to cost and emissions savings. The method is applied to evaluate the allocation of economic and environmental benefits of vendor-managed inventory between cooperating supermarket chains in the Netherlands. The findings show that there is a set of eco-efficient solutions resulting in lower costs and $\mathrm{CO}_{2}$ emissions compared to the current situation. For each of the eco-efficient solutions, the relative importance of saving costs and of saving emissions was quantified, and based on the importance weights, a cost allocation was found. For all partners that contribute to saving both cost and $\mathrm{CO}_{2}$ emissions, this approach results in cost savings, and therefore, the approach can be considered fair.
\end{abstract} Also, this approach helps to stimulate long-term eco-efficient forms of cooperation.

Keywords: logistics, routing, cooperative game theory, trade-off, cooperation

\footnotetext{
*corresponding author

Email addresses: heleen.stellingwerf@wur.nl (H.M. Stellingwerf), argyris.kanellopoulos@wur.nl (A. Kanellopoulos), f.cruijssen@argusi.org (F.C.A.M.Cruijssen), jacqueline.bloemhof@wur.nl (J.M. Bloemhof)
} 
Table 1 summarises the abbreviations used in this study.

Table 1: Glossary

\begin{tabular}{ll}
\hline Abbreviation & Explanation \\
\hline CDC & Central Distribution Centre \\
CGT & Cooperative Game Theory \\
$\mathrm{CO}_{2}$ & Carbon dioxide \\
$\mathrm{DC}$ & Distribution Centre \\
$\mathrm{IRP}$ & Inventory Routing Problem \\
JRP & Joint Route Planning \\
VMI & Vendor Managed Inventory \\
VRP & Vehicle routing problem \\
\hline
\end{tabular}

\section{Introduction}

Public awareness about global environmental changes such as air pollution caused by intensified economic activity has increased the demand for goods and services that reduce environmental impact (Garnett, 2008, Hariga et al., 2017). To remain competitive, current supply chains must be re-designed and become more eco-efficient. In other words, they need to decrease the environmental impact for the same or even lower cost (Banasik et al., 2016). A major source of inefficiency of current supply chains is related directly to transportation, which is responsible for $14 \%$ of total $\mathrm{CO}_{2}$ emissions both at global and EU level (Dekker et al., 2012). Cooperative logistics has been suggested as a way of reducing $\mathrm{CO}_{2}$ emissions and of improving sustainability in supply chains (McKinnon, 2016, Ramanathan et al., 2014, Vanovermeire et al., 2014, Chen et al., 2017). This is mainly because cooperation improves the utilisation rate of vehicles at it allows cooperating companies to exploit the synergies between them (Cruijssen et al., 2007b). A report from 2012 showed that the average loading rate of vehicles is $56 \%$ in terms of weight, and combining loads could thus decrease the number of vehicles driving around, which can help reducing costs and $\mathrm{CO}_{2}$ emissions (Cruijssen, 2012).

Vendor-managed inventory (VMI) is a form of cooperation in which a vendor manages its own inventory as well as the inventory of its customer(s) by taking decisions on the replenishment quantity and frequency. The vendor is also responsible for keeping the stock level of the customer within agreed limits (Nagarajan and Sošić, 2008). VMI cooperation can result in substantial economic and environmental benefits because both transportation and inventory planning decisions can be optimised jointly (Stellingwerf et al., 2018b). Successful 
long term VMI that aims to improve eco-efficiency of the supply chain requires a fair distribution of economic benefits or costs based not only on the contribution of each participant to the shared cost savings but also to the shared environmental savings (Stellingwerf et al., 2018b).

Cooperative game theory (CGT) methods have been used to identify a fair allocation of the benefits of cooperation in supply chains. CGT methods generally focus on allocation of economic benefits based on the contribution of the participants to improve the economic performance of the cooperation (Frisk et al., 2010). Recently, a commonly used CGT method, the Shapley value (Shapley, 1953) has been applied to allocate emissions in cooperative transportation (Naber et al., 2015). However, the possibility to use CGT methods to allocate the economic benefits based on both the economic and environmental contribution of participants has not been explored; CGT methods have mainly been used either for economic or for environmental allocation (Guajardo, 2018). The objective of this study is to propose a methodology for allocating economic benefits of VMI based on both the economic and environmental contributions of participants, such that both contributions are rewarded and eco-efficient forms of cooperation are stimulated. The proposed methodology is used to distribute economic benefits of VMI cooperation in supermarket chains in the Netherlands. The remainder of the paper is organised as follows. Section 2 provides the theoretical framework; Section 3, describes the proposed methods; Section 4 describes a case study; Section 5 describes the results; and in Section 6, the main conclusions are presented.

\section{Theoretical framework}

\subsection{Quantifying benefits of cooperation}

Literature has shown that logistics cooperation can bring significant benefits to cooperating partners (Cruijssen et al., 2007b), such as cost reductions and efficiency gains (Adenso-Díaz et al., 2014). The review of Chen et al. (2017) suggests that until recently, cooperation studies have focused on monetary benefits but there is a trend towards measuring or estimating the environmental impacts of supply chain cooperation as well. For example, Ramanathan et al. (2014) qualitatively evaluated how the environmental pressure from different stakeholders can help to improve supply chain cooperation, which in turn can lead to improved business performance. 
Cooperative benefits have also been studied qualitatively. Stellingwerf et al. (2018b) have evaluated different forms of cooperation and they have quantitatively shown that VMI is an advanced form of cooperation that can provide significant cost and emission savings. In order to quantify benefits of VMI, models based on the inventory routing problem (IRP) can be used because in these models routing and inventory decisions are optimised simultaneously (Coelho et al., 2013). In general, IRP models minimise cost, which are calculated by adding inventory, transportation, and labour cost. Stellingwerf et al. (2018b) used an IRP model to quantify both the economic and environmental effects of cooperation in fresh food logistics. This model will be used in this study as well; it will be briefly explained in the next section and completely formulated in the Appendix. It was found that VMI can bring significant benefits to partners, since both transportation and inventory are optimised. After total cooperative benefits have been quantified, they have to be distributed among the partners, and this is the role of cooperative game theory.

\subsection{Allocation of cost and $\mathrm{CO}_{2}$ emissions in supply chain cooperation}

In order to ensure that a cooperation is successful in the long run, it is important that the associated cost and the resulting gains are allocated in a way that is considered fair by all participants (Cruijssen et al., 2007a). CGT methods have been used to identify potential coalitions, to quantify the total benefits of these coalitions, and to fairly allocate the benefits of the coalitions to all cooperating partners (Nagarajan and Sošić, 2008). In most CGT methods, the benefits or cost allocated to a partner are related to the partner's contribution to the group's cost savings (Guajardo and Rönnqvist, 2016). Different CGT methods exist and Tijs and Driessen (1986) have summarised them. The most common methods are the Shapley value, the nucleolus, the equal charge method, the alternative cost avoided method, and the cost gap method. Recent case studies that compare different cost allocation methods are, for example, Frisk et al. (2010), Vanovermeire et al. (2014), and Wang et al. (2017). Frisk et al. (2010) applies different cost allocation methods (the equal profit method that they developed themselves and the and Shapley value based methods) to a case study on cooperative wood transportation by different forest companies. They find similar allocations in both methods, but they argue that the equal profit method is easier to understand. Vanovermeire and Sörensen (2014) argue that flexibility is crucial in horizontal logistics cooperation, and they test different allocation methods on their ability to reward flexibility of cooperating partners. They discuss that the Shapley value, the nucleolus and 
the equal charge method give consistent and fair incentives for flexibility. Wang et al. (2017) allocate cooperative vehicle routing cost savings using the Shapley value.

The above-mentioned studies focus on transport cooperation. Allocation of benefits in VMI cooperation (joint optimisation of both transportation and inventory decisions) has only been studied in the work of Özener et al. (2013). They compare different cost allocation methods for VMI cooperation in a case study where cost-to-serve has to be split between clients. They propose different methods which perform better than proportional allocation methods, which have often been discussed to not result in fair allocations. However, this study does not consider environmental effects of VMI cooperation, and neither does it study how those environmental benefits could be used in allocation decisions.

There are some gain allocation studies that conclude that logistics cooperation results in cost savings as well as environmental benefits (Frisk et al., 2010, Vanovermeire et al., 2014, Jonkman et al., 2018). Other recent studies have started to use gain allocation methods to allocation $\mathrm{CO}_{2}$ emissions to cooperating partners (Kellner and Otto, 2012, Naber et al., 2015, Zhu et al., 2016). Some authors include $\mathrm{CO}_{2}$ emissions as part of the cost function, on which they apply different allocation methods (Özener, 2014, Niknamfar and Niaki, 2016, Sanchez et al., 2016). Guajardo (2018) studied cooperative logistics in a cost minimising as well as in an emission minimising setting. In a small 3-partner problem, costs and emissions are minimising separately. For the cost minimising solution, costs are allocated using the proportional method, the Shapley method, and the Nucleolus. And for the emission minimising solutions, emissions are allocated using the same methods. Despite the small problem size, the optimal solution for cost and emission minimisation is different, a different optimal route is found.

Despite the efforts that have been done to quantify and distribute the benefits of cooperation, the contribution of a partner to reduce the $\mathrm{CO}_{2}$ emissions of the cooperation is has not been translated to economic benefits, which is the gap this study attempts to address. In order to engage partners in the improvement of the eco-efficiency of their supply chain through cooperation, the partners should not only be rewarded based on their contribution to cost savings of the coalition but also based on their contribution to emissions savings. Table 2 summarises the studies discussed in the theoretical framework.

From Table 2, it can be seen that the Shapley value is a the most commonly used CGT method in the discussed studies. According to Guajardo and Rönnqvist (2016), who review 
Table 2: Overview of literature discussed. Abbreviations: JRP, joint route planning; ECM, equal charge method; ACAM, alternative cost avoided method; EPM, equal profit method; CVMI, cooperative vendor-managed inventory.

\begin{tabular}{|c|c|c|c|c|}
\hline Authors & $\begin{array}{l}\text { Form of } \\
\text { cooperation }\end{array}$ & $\begin{array}{l}\text { Economic } \\
\text { quantification }\end{array}$ & $\begin{array}{l}\text { Environmental } \\
\text { quantification }\end{array}$ & $\begin{array}{l}\text { Allocation methods } \\
\text { studied }\end{array}$ \\
\hline Kellner and Otto (2012) & JRP & no & yes & 15 different ones including Shapley \\
\hline Nagarajan and Sošić (2008) & CVMI & yes & no & Nash bargaining problem \\
\hline Frisk et al. (2010) & JRP & yes & no & $\begin{array}{l}\text { Volume, Shapley, shadow, ECM } \\
\text { ACAM, nucleolus, EPM }\end{array}$ \\
\hline Özener et al. (2013) & CVMI & yes & no & Duality based methods, Shapley value \\
\hline Özener (2014) & JRP & yes & yes & $\begin{array}{l}\text { duality and Shapley value based } \\
\text { allocation mechanism }\end{array}$ \\
\hline Naber et al. (2015) & JRP & no & yes & $\begin{array}{l}\text { Proportional, star, Shapley } \\
\text { Nucleolus, Lorenz, EPM }\end{array}$ \\
\hline Niknamfar and Niaki (2016) & JRP & yes & yes & dual lexicographic max-min approach \\
\hline Sanchez et al. (2016) & JRP & yes & yes & Shapley \\
\hline Zhu et al. (2016) & JRP & no & yes & $\begin{array}{l}\text { Shapley, transport work based, } \\
\text { distance based, cargo volume based }\end{array}$ \\
\hline Palhazi Cuervo et al. (2016) & JRP & yes & no & Proportional \\
\hline
\end{tabular}

gain allocation methods in cooperative transportation, this is because the Shapley value satisfies important fairness properties. Moreover, despite the fact that the Shapley solution is not guaranteed to be in the core (i.e. the gain allocation of all players within a certain coalition is better compared to their allocation in all other possible smaller coalitions or the non-cooperative solution) in most of the studies discussed in the review of Guajardo and Rönnqvist (2016), the Shapley was found to be a core solution. Finally, Cruijssen et al. (2010) propose Shapley as a practical CGT method because it is easy to interpret and communicate with the decision makers. In the study of Vanovermeire and Sörensen (2014), the Shapley value was used in a case study and it was found that it gave incentives to cooperate. Because of the appealing properties of the Shapley value and its broad use in CGT literature, it is attractive from a practical as well as a scientific point of view. Therefore, this study uses the Shapley value as well.

\subsection{Benefit allocation using the Shapley value}

The Shapley value (Shapley, 1953) is one of the most common gain sharing rules in the literature since it provides a unique solution to the allocation problem and it satisfies appealing fairness properties (Lozano et al., 2013). Almost all studies discussed use (amongst others) the Shapley value. The Shapley method will be used in this study as it will allow 
for comparison with the other studies. The Shapley value provides an allocation for all cooperative partners based on each partner's contribution to the total costs or benefits of the group and it is calculated as:

$$
y_{j}=\sum_{S \subseteq N \backslash\{j\}} \frac{(|S|-1) !(|N|-|S|) !}{|N| !}[c(S)-c(S-\{j\})],
$$

where $N$ is the group in which all partners participate, which is called grand coalition. $S$ is any sub-coalition by the partners of the grand coalition, and $y_{j}$ is value allocated to partner j. $C(S)$ is the value (e.g. costs or $\mathrm{CO}_{2}$ emissions) of coalition $S, c(S-\{j\})$ is the value of coalition $\mathrm{S}$ without partner $j$. Therefore, $c(S)-c(S-\{j\})$ is the amount by which the value of coalition $c(S-\{j\})$ increases when participant $j$ joins the coalition, i.e. the marginal value of participant $j$. The Shapley value allocated to a partner (Eq. 1) can be interpreted as the average marginal contribution that partner brings to the group (Shapley, 1953). In order to calculate the Shapley value, it is necessary to know the value of all possible sub coalitions that can be formed from the grand coalition. These values are called the characteristic function. For more information on the Shapley value, the interested reader is referred to Shapley (1953).

\section{Methodology}

In order to establish an allocation based on both cost and $\mathrm{CO}_{2}$ emissions, a three-step methodology is proposed, summarised in Figure 1. In the first step, the set of eco-efficient solutions is calculated using the green IRP model proposed by Stellingwerf et al. (2018b) because it optimises inventory and routing decisions simultaneously by minimising either the environmental impact or the costs of a potential coalition. The IRP is an extension of the better-known Vehicle Routing Problem (VRP). In the basic VRP model, the objective is to identify the shortest route for visiting a set of individual customers. Generally, travelling distance is minimised given (a) vehicle(s) that has to leave and return to a depot and deliver demand to a number of customers. Constraints are used to limit the carrying capacity of the vehicles. Lately, variants of the VRP have been developed where the objective function is formulated such that costs and/or emissions can be minimised instead of distance. A VRP can be used to solve one-period routing problems. In the IRP, not only routing, but also inventory decisions are optimised simultaneously. The constraints of the IRP are the same 
as the VRP, but constraints that define the inventory at the depot and the demand locations are added, as well as inventory capacity constraints. The IRP can be used for multi-period routing and inventory problems: if there is enough inventory in the demand locations, less frequent routing with higher volumes could be considered.

In order to estimate emissions $E\left(\mathrm{~kg} \mathrm{CO}_{2}\right)$ using an IRP model, the fuel use is calculated since it is assumed to be linearly related to $\mathrm{CO}_{2}$ emissions. Fuel use in road transport depends on the weight carried, the slope of the road, the distance travelled, the air density, and the vehicle speed (Bektaş and Laporte, 2011). The cost $C(€)$ is calculated by adding wage cost, fuel cost, and inventory holding cost.

\begin{tabular}{|c|c|c|c|c|}
\hline & \multirow{2}{*}{$\begin{array}{l}\text { Price of emissions } \\
\text { for each eco- } \\
\text { efficient solution }\end{array}$} & \multirow{3}{*}{$\begin{array}{l}\text { 2. IRP to calculate cost } \\
\text { and emissions of all } \\
\text { possible coalitions }\end{array}$} & Cost and & \\
\hline \multirow{2}{*}{$\begin{array}{l}\text { 1. IRP to calculate eco- } \\
\text { efficient solutions }\end{array}$} & & & $\begin{array}{l}\text { emissions for each } \\
\text { sub coalition }\end{array}$ & \multirow{2}{*}{$\begin{array}{l}\text { 3. Calculate Shapley } \\
\text { cost and emission- } \\
\text { based benefit } \\
\text { allocation }\end{array}$} \\
\hline & & & & \\
\hline
\end{tabular}

Figure 1: Summary of the methodology used in this study to arrive to a cost and $\mathrm{CO}_{2}$ emissions based Shapley allocation.

The IRP constraints can be subdivided in three main types: (i) inventory constraints: they impose minimum and maximum levels of the inventory of the depot and the destinations in each period considering an initial inventory level; (ii) vehicle routing constraints: they impose that a delivery can be made to a location only if it is visited by a vehicle, and that a vehicle cannot visit the same location multiple times in the same time period, they restrict the number of vehicles used per day, and they define vehicle capacity; (iii) flow constraints: these define how the load of the vehicle changes after visiting a location, eliminate sub tours, and define impossible arcs. The mathematical formulation of the IRP model and the calculations of the cost and $\mathrm{CO}_{2}$ emissions are presented in the Appendix. In that section, the parameters used in the IRP model are also summarised, and the values used to run the model are given. The IRP model was coded and solved with Fico Xpress Mosel version 8.0 on a PC with Intel Core i5 processor $(2.6 \mathrm{GHz})$ and eight GB of RAM memory.

In the first step, in order to find a representative set of eco-efficient intermediate solutions that minimise costs and emissions, the weighing method proposed by Romero and Rehman (2003) is used, which is a commonly used method in goal programming. This is a convenient method as the $\lambda$ value needed for the weighing method can also be used later in the gain 
allocation method. An additive objective function is formulated (Eq. 2) subject to the constraints of the above mentioned IRP model.

$$
\text { Minimise } K=C+\lambda E \text {, }
$$

where $K$ is the additive objective function value $(€), C$ is the cost $(€), \lambda$ is the price of $\mathrm{CO}_{2}$ emissions $(€ / \mathrm{kg})$, which can also be interpreted as the relative importance of saving $\mathrm{CO}_{2}$ emissions as compared to saving cost, $E$ are the $\mathrm{CO}_{2}$ emissions (kg). By varying $\lambda$, the alternative optimal (eco-efficient) solutions can be found.

The set of eco-efficient solutions is calculated by changing the values of $\lambda$. The higher the value of $\lambda$, the more importance is attached to the environmental indicator E. The model is run in an iterative way, starting with $\lambda$ (which results in the cost minimising solution) and the value of $\lambda$ is increased in steps of 0.1 until the emission minimising solution is found. The value of lambda leading to an eco-efficient solution is used as the price of emissions when calculating the benefit allocation of that eco-efficient solution. If there is a range of $\lambda$ values leading to the same solution, the average of that range $\bar{\lambda}$ is used for the gain allocation step.

In the second step, the $\bar{\lambda}$ value of each eco-efficient solution is used in the IRP model to calculate the minimum K-value for each possible sub-coalition that can be formed from the cooperating participants. This way, for each $\bar{\lambda}$ value, the characteristic function of the Shapley value (Eq. 1) is calculated.

In step three, the characteristic function is used to allocate the K-value benefits to the partners using the Shapley value (see Eq. 1). The K-value can be converted back to costs, which are easier to interpret, using the following equation:

$$
y_{j}^{c}=\frac{y_{j}^{k} \times C}{K},
$$

where $y_{j}^{k}$ is the K-value allocated to partner $j(€), y_{j}^{c}$ is the cost allocated to partner $j(€)$, With this procedure, the total costs of an eco-efficient solution are divided over the partners. No extra costs are paid for emissions, but when $\lambda$ chosen such that the costminimising solution is not optimal, the contributions of the partners to saving emissions are also considered in the cost allocation. The higher the value of $\lambda$, the higher the advantage for partners that help save emissions. 
After this three-step procedure, all eco-efficient solutions, the prices of $\mathrm{CO}_{2}$ emissions that lead to that solutions, and the allocations based on those emissions prices are calculated. The cooperative costs (savings) are allocated among the partners, but the cooperative emissions are not since the partners have agreed to regard that as a group benefit: if the group saves $40 \%$ of emissions, all partners can claim that they save $40 \%$ of emissions by cooperating. In this study, the allocation of benefits based on both costs and emissions is done using the Shapley value, but other gain allocation methods could be used as well.

The generation of all possible sub-coalitions of step 2 as well as the Shapley value calculations of step 3 were coded in $\mathrm{R}$ (version i386 3.2.1) on a PC with Intel Core i5 processor $(2.6 \mathrm{GHz})$ and eight GB of RAM memory.

\section{Case study: VMI for eco-efficient food distribution in the Netherlands}

\subsection{Data and assumptions}

The case study is based on seven supermarket chains in the Netherlands. Currently, they cooperate by buying their products together in order to negotiate a lower unit price. The cooperatively bought products are delivered to their shared central distribution centre (CDC, denoted by 0). From there, the supermarket chains arrange their logistics separately. They individually pick up (or use a logistics service provider to pick up) the products from the $\mathrm{CDC}$ and bring them to their distribution centres (DCs, denoted by $1-7$ ). The supermarket chains aim to further cooperate by implementing VMI between the CDC and the DCs to reduce cost and $\mathrm{CO}_{2}$ emissions. They consider to allocate the resulting economic gains by accounting for their contribution to reducing both cost and $\mathrm{CO}_{2}$ emissions of the coalition.

The distances between the CDC and the DCs are presented in Table 3. The aggregate weekly demand of a representative set of fresh food products of each DC (in $\mathrm{kg}$ ) is presented in Table 4. Note that there is no demand on Sunday because the CDC and the DCs are closed on that day. On some days, there is no demand (the zeroes in Table 4) because some DCs do not place orders every day. Other values used to run the IRP model can be found in Table 10 in the Appendix. 
Table 3: Distances (in $\mathrm{km}$ ) between the DCs of the supermarket chains (denoted by 1-7) and the CDC (denoted by 0$)$

\begin{tabular}{r|rrrrrrrr} 
DC & 0 & 1 & 2 & 3 & 4 & 5 & 6 & 7 \\
\hline 0 & 0 & 91 & 6 & 134 & 82 & 117 & 74 & 192 \\
1 & 91 & 0 & 91 & 75 & 134 & 43 & 20 & 155 \\
2 & 6 & 91 & 0 & 134 & 84 & 117 & 75 & 194 \\
3 & 134 & 75 & 134 & 0 & 168 & 46 & 94 & 90 \\
4 & 82 & 134 & 84 & 168 & 0 & 158 & 140 & 180 \\
5 & 117 & 43 & 117 & 46 & 158 & 0 & 59 & 117 \\
6 & 74 & 20 & 75 & 94 & 140 & 59 & 0 & 174 \\
7 & 192 & 155 & 194 & 90 & 180 & 117 & 174 & 0
\end{tabular}

Table 4: Aggregate demand in kg at each DC (1-7).

\begin{tabular}{l|rrrrrr} 
& Monday & Tuesday & Wednesday & Thursday & Friday & Saturday \\
\hline 1 & 540 & 540 & 450 & 450 & 810 & 0 \\
2 & 1890 & 1680 & 1260 & 2760 & 2220 & 1170 \\
3 & 270 & 630 & 360 & 540 & 1440 & 0 \\
4 & 0 & 1122 & 0 & 1248 & 0 & 0 \\
5 & 1260 & 810 & 1350 & 1260 & 540 & 1080 \\
6 & 1170 & 1524 & 1170 & 1608 & 2412 & 0 \\
7 & 0 & 720 & 360 & 720 & 360 & 450
\end{tabular}

\subsection{Setup of calculations}

In order to establish a Shapley allocation based on both the environmental and the economic contributions of the partners, the three-step method described in Figure 1 is followed. First, the data described above are input to an IRP model (Stellingwerf et al., 2018 b) with the aggregate objective function (Eq. 2) to find the eco-efficient cooperative solutions (Romero and Rehman, 2003). To find all these solutions, the IRP model is run iteratively with an increasing value of $\lambda$, with a step size of 0.1 . The weighing method (which uses an additive objective functions) results in an optimal solution for each $\lambda$. As these $\lambda$ values directly correspond with the price of emissions, it can also be used in the rest of the calculations. For each eco-efficient solution, the corresponding average price of emissions $(\bar{\lambda})$ is determined. Second, the IRP model is solved for all possible sub-coalitions and for all different eco-efficient solutions (using the different values of $\bar{\lambda}$ ). And third, the Shapley value is calculated based using the characteristic function calculated in step 2. The Shapley allocation based on the K-value is translated to the actual cost. Finally, the savings in terms of the additive objective function value $\mathrm{K}$, and in terms of cost for all groups and for all individuals are calculated using Eq. (3). 
To assess the potential benefits of VMI cooperation the allocations of each eco-efficient solution are compared to the current situation. To estimate the current allocations, costs are minimised using the IRP model while imposing that each supermarket chain optimises transportation separately. To better understand the impact of important model parameters such as the distance between DCs and CDC and the demand of the SC one of the eco-efficient solutions found is used to test a set of alternative scenarios is explored. These scenarios test the effect of distance and demand. Table 5 summarises the scenarios. In this table, base refers to one of the solutions found optimising the additive objective function given the demand and distance data in Table 3 and 4 . In this table equal distance refers to the situation where all partners are located equally far from the CDC, but the total distance of the matrix is still the same as in the base case scenarios (illustrated in Figure 2). Equal demand refers to the situation where the total demand of all partners is equal $(1 / 7$ of the group demand), but the week structure is kept (i.e. if $14 \%$ of the total demand is on Monday in the base case, that is still the case in the equal demand situations).

Table 5: The scenarios used to assess the impact of distance and demand.

\begin{tabular}{cll}
\hline Scenario & Distance & Demand \\
\hline 1 & Base & Base \\
2 & Equal & Equal \\
3 & Base & Equal \\
4 & Equal & Base \\
\hline
\end{tabular}

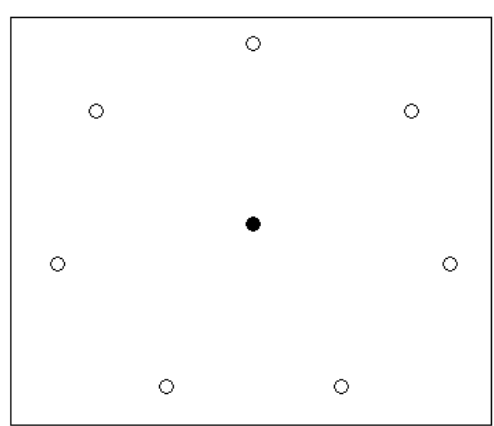

Figure 2: Uniform distance distribution of locations. Black point indicates CDC, white points indicate DCs. 


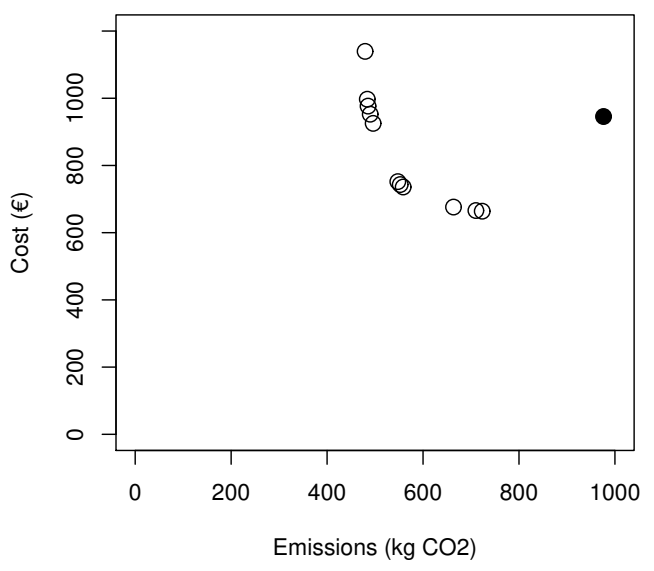

Figure 3: $\mathrm{CO}_{2}$ emissions $(\mathrm{kg})$ and cost $(€)$ for the cooperative solution options and the current situation.

\section{Results and discussion}

\subsection{Analysis of the eco-efficient solutions}

Using the IRP model with the additive objective function, the eco-efficient solutions were calculated. Figure 3 shows the cost and $\mathrm{CO}_{2}$ emissions of all calculated eco-efficient solutions and of the current situation: 11 discrete eco-efficient cooperative solutions were calculated. All this solutions are optimal and depend on the importance allocated to the two objectives through the value of lambda. To find these solutions, the model was run in multiple iterations with a range of lambda values (0-40 with a step size of 0.1$)$. Values of $\lambda$ above 31.6 result in the emission-minimising solution. For all other solutions, there was a range of $\lambda$ values leading to that solution.

The 11 eco-efficient solutions found were labelled as $s 1$ for the emission minimising solution to $s 11$ for the cost-minimising solution. Table 6 shows the $\mathrm{CO}_{2}$ emissions, costs, distance, travelling time and the number of trips related to each eco-efficient solution, as well as the current situation. Since there was a range of lambdas leading to the different solutions, only the averages of each solution range are shown.

Table 6 shows that all cooperative eco-efficient solutions result in less $\mathrm{CO}_{2}$ emissions compared to the current situation. Solutions $s 5$ to $s 11$ correspond to lower costs than the current situation. Moreover, minimising $\mathrm{CO}_{2}$ emissions results in a solution in which products 
Table 6: Current solution and the eco-efficient solutions.

\begin{tabular}{|c|c|c|c|c|c|c|c|c|c|c|c|c|}
\hline & current & s1 & s2 & s3 & $\mathrm{s} 4$ & s5 & s6 & s7 & $\mathrm{s} 8$ & s9 & s10 & s11 \\
\hline $\bar{\lambda}$ & 0 & 31.6 & 22.25 & 9.15 & 4.95 & 3.95 & 2.60 & 1.50 & 0.90 & 0.45 & 0.25 & 0.10 \\
\hline $\mathrm{CO}_{2}$ emissions $(\mathrm{kg})$ & 976 & 479 & 484 & 485 & 490 & 496 & 547 & 552 & 559 & 664 & 710 & 723 \\
\hline Costs $(€)$ & 946 & 1139 & 997 & 977 & 953 & 925 & 752 & 743 & 736 & 676 & 666 & 664 \\
\hline - Transportation cost $(€)$ & 512 & 252 & 254 & 255 & 257 & 260 & 287 & 290 & 293 & 348 & 373 & 380 \\
\hline - Inventory cost $(€)$ & 433 & 888 & 743 & 722 & 695 & 665 & 465 & 453 & 443 & 328 & 293 & 284 \\
\hline Distance (km) & 1837 & 808 & 816 & 820 & 828 & 841 & 931 & 938 & 950 & 1168 & 1215 & 1241 \\
\hline Travelling time (h) & 29.0 & 13.0 & 13.3 & 13.4 & 13.8 & 14.2 & 16.2 & 16.5 & 16.9 & 20.5 & 21.6 & 22.2 \\
\hline Number of trips & 14 & 4 & 4 & 5 & 5 & 6 & 6 & 6 & 7 & 8 & 7 & 8 \\
\hline
\end{tabular}

are delivered less frequently. On the other hand, minimising cost results in a solution in which the companies are supplied more frequently, since this reduces their inventory cost. This is also reflected in the decrease in transportation cost and an increase in inventory cost when the price of $\mathrm{CO}_{2}$ emissions $(\bar{\lambda})$ increases. Moreover, it is illustrated by the change in the number of trips, the distance driven and the driving time.

\subsection{Shapley allocation of the K-value and costs}

Table 7 provides the current uncooperative costs and $\mathrm{CO}_{2}$ emissions, as well as the total savings in $\mathrm{CO}_{2}$ emissions for each solution and the cost allocation based on the K-value for each participant in each eco-efficient solution. Also, it shows the percentage allocated to each partner in each solution. Since Eq. (3) is used to convert the K-allocation to costs using a fixed factor (the K-allocation of a partner divided by the total K-value), the percentage of total allocation will be the same whether this is cost, emissions or K-value.

Table 7: Current costs $(€)$ and emissions $(\mathrm{kg} \mathrm{CO}$, and total emission savings $(\%)$ costs $(€)$ and percentage of the K-value (\%) allocated for all eco-efficient solutions

\begin{tabular}{|c|c|c|c|c|c|c|c|c|c|c|c|c|}
\hline \multirow{2}{*}{\multicolumn{3}{|c|}{$\begin{array}{l}\text { Solution } \\
\text { E saving }\end{array}$}} & \multicolumn{2}{|c|}{ s1 } & \multicolumn{2}{|c|}{ s2 } & \multicolumn{2}{|c|}{ s3 } & \multicolumn{2}{|c|}{ s4 } & \multicolumn{2}{|c|}{ s5 } \\
\hline & & & \multicolumn{2}{|c|}{$51 \%$} & \multicolumn{2}{|c|}{$50 \%$} & \multicolumn{2}{|c|}{$50 \%$} & \multicolumn{2}{|c|}{$50 \%$} & \multicolumn{2}{|c|}{$49 \%$} \\
\hline & Indi & dual & & & & & & & & & & \\
\hline Partner & $\mathrm{C}$ & $\mathrm{E}$ & $\mathrm{C}$ & $\mathrm{K}$ & $\mathrm{C}$ & K & $\mathrm{C}$ & $\mathrm{K}$ & $\mathrm{C}$ & K & $\mathrm{C}$ & $\mathrm{K}$ \\
\hline 1 & 113 & 96 & 106 & 9 & 92 & 9 & 89 & 9 & 87 & 9 & 84 & 9 \\
\hline 2 & 58 & 39 & 38 & 3 & 36 & 4 & 45 & 5 & 54 & 6 & 55 & 6 \\
\hline 3 & 166 & 143 & 170 & 15 & 148 & 15 & 143 & 15 & 138 & 14 & 133 & 14 \\
\hline 4 & 75 & 86 & 177 & 16 & 153 & 15 & 143 & 15 & 131 & 14 & 124 & 13 \\
\hline 5 & 208 & 249 & 189 & 17 & 167 & 17 & 167 & 17 & 167 & 18 & 165 & 18 \\
\hline 6 & 168 & 162 & 165 & 15 & 147 & 15 & 152 & 16 & 155 & 16 & 154 & 17 \\
\hline 7 & 158 & 202 & 294 & 26 & 254 & 25 & 237 & 24 & 220 & 23 & 210 & 23 \\
\hline sum & 946 & 976 & 1139 & 100 & 997 & 100 & 977 & 100 & 953 & 100 & 925 & 100 \\
\hline
\end{tabular}


Table 7: Current cost $(€)$, and costs $(€)$ and percentage of the K-value (\%) allocated for all eco-efficient solutions (continued)

\begin{tabular}{|c|c|c|c|c|c|c|c|c|c|c|c|c|c|c|}
\hline \multirow{2}{*}{\multicolumn{3}{|c|}{$\begin{array}{l}\text { solution } \\
\text { E saving }\end{array}$}} & \multicolumn{2}{|c|}{$\mathrm{s} 6$} & \multicolumn{2}{|c|}{ s7 } & \multicolumn{2}{|c|}{$\mathrm{s} 8$} & \multicolumn{2}{|c|}{ s9 } & \multicolumn{2}{|c|}{$\mathrm{s} 10$} & \multicolumn{2}{|c|}{ s11 } \\
\hline & & & \multicolumn{2}{|c|}{$44 \%$} & \multicolumn{2}{|c|}{$43 \%$} & \multicolumn{2}{|c|}{$43 \%$} & \multicolumn{2}{|c|}{$32 \%$} & \multicolumn{2}{|c|}{$12 \%$} & \multicolumn{2}{|c|}{$26 \%$} \\
\hline & Indi & dual & & & & & & & & & & & & \\
\hline Partner & $\mathrm{C}$ & $\mathrm{E}$ & $\mathrm{C}$ & $\mathrm{K}$ & $\mathrm{C}$ & $\mathrm{K}$ & $\mathrm{C}$ & $\mathrm{K}$ & $\mathrm{C}$ & $\mathrm{K}$ & $\mathrm{C}$ & $\mathrm{K}$ & $\mathrm{C}$ & $\mathrm{K}$ \\
\hline 1 & 113 & 96 & 66 & 9 & 64 & 9 & 66 & 9 & 61 & 9 & 71 & 9 & 58 & 9 \\
\hline 2 & 58 & 39 & 48 & 6 & 52 & 7 & 54 & 7 & 51 & 8 & 64 & 8 & 55 & 8 \\
\hline 3 & 166 & 143 & 109 & 14 & 109 & 15 & 111 & 15 & 103 & 15 & 124 & 15 & 103 & 16 \\
\hline 4 & 75 & 86 & 97 & 13 & 92 & 12 & 86 & 12 & 77 & 11 & 89 & 11 & 72 & 11 \\
\hline 5 & 208 & 249 & 137 & 18 & 139 & 19 & 141 & 19 & 132 & 20 & 161 & 20 & 132 & 20 \\
\hline 6 & 168 & 162 & 129 & 17 & 130 & 18 & 128 & 17 & 115 & 17 & 138 & 17 & 113 & 17 \\
\hline 7 & 158 & 202 & 165 & 22 & 158 & 21 & 150 & 20 & 137 & 20 & 162 & 20 & 132 & 20 \\
\hline sum & 946 & 976 & 752 & 100 & 744 & 100 & 736 & 100 & 676 & 100 & 808 & 100 & 664 & 100 \\
\hline
\end{tabular}

The percentage of benefits allocated to partner 1 remains the same in all calculated eco-efficient solutions; partner 1 may equally contribute to saving cost and to saving $\mathrm{CO}_{2}$ emissions. For partner 2, 5, and 6 there is an increase in the allocation when moving from s1, the $\mathrm{CO}_{2}$ minimising solution, to s11, the cost minimising solution. Apparently partner 2, 5, and 6 are more helpful in saving $\mathrm{CO}_{2}$ compared to the other partners. These partners have a relatively high demand, but not too high to limit to possibility to combine their demand with other demands. Moreover, they are located close to the CDC and their demand is spread well over the week. These aspects make it easy to combine these partners in cooperative routes.

For partner 3, the emission allocation is relatively stable from s1 to s5 but from s6 to s11, when the price of $\mathrm{CO}_{2}$ increases further, partner 3 is allocated an increased amount of emissions. Apparently partner 3 does not contribute that much to saving emissions in comparison to the other partners. This might relate to the fact that partner 3 is located relatively far from the CDC. The cost allocation results (Table 7) show that partner 4 does not save cost in any solution except for solution s11, the cost minimising solution. The demand of partner 4 is relatively low, and this partner only has demand on two days of the week. This might limit the opportunities for making cooperative route, which is why the benefits allocated to this partner are also relatively low. For solution s1 to s8 (when the price of emissions is higher than $0.90 € / \mathrm{kg}$ ), partner 7 is faced with a cost increase. Partner 7 is located the furthest from the CDC, which is why this partner does not contribute much to saving emissions, and why this partner only benefits when the price of emissions is low. 


\subsection{The effects of distance and demand on the allocation}

To assess the impact of different demand and distance scenarios on the calculated allocation, the eco-efficient solution $s 8$, which has a $\bar{\lambda}$ value of 0.9 , was further analysed. The total cost and $\mathrm{CO}_{2}$ emissions of this solution are $€ 559$ and $736 \mathrm{~kg}$, respectively. This solution is a non-extreme, balanced solution between cost and $\mathrm{CO}_{2}$ emissions. These scenarios could also be tested on any other eco-efficient solution. Table 8 provides the resulting allocations.

Table 8: The benefit allocations (\%) resulting from the distance and demand scenarios.

\begin{tabular}{cllrrrrrrr}
\hline & & & \multicolumn{10}{c}{ Partner } \\
\hline Scenario & Distance & Demand & 1 & 2 & 3 & 4 & 5 & 6 & 7 \\
\hline 1 & Base & Base & 9.0 & 7.3 & 15.1 & 11.6 & 19.2 & 17.4 & 20.4 \\
2 & Equal & Equal & 14.3 & 14.3 & 14.3 & 14.3 & 14.3 & 14.3 & 14.3 \\
3 & Base & Equal & 12.0 & 4.1 & 16.3 & 17.6 & 14.0 & 11.3 & 24.7 \\
4 & Equal & Base & 10.2 & 22.9 & 12.0 & 8.5 & 16.6 & 19.5 & 10.3 \\
\hline
\end{tabular}

When all distances to the DC are equal and all demands are equal, the resulting allocation is equal for every partner (Table 8). This result is inherent to the Shapley value, because it has the symmetry property: if a partner contributes the same as an other partner, the allocation of those partners should be the same. Partner 4 and 7 do not always benefit from the allocation (see Table 7). The results of the demand and distance scenarios can help explain why this is the case. In the base case, partner 4 is relatively far from the other DCs. Therefore, the equal-distance cases cause a lower allocation for partner 4 . Partner 4 also has a low demand and only has demand on two days in the base case. This probably causes partner 4 to have a limited number of cooperation possibilities which is why this partner can also not benefit that much from cooperation. Note that the relative allocation to partner 4 is not high but since the demand is low, the allocation per unit is relatively high.

Partner 7 is located very far from the CDC in the base case. Therefore, a reduction in distance (as in the equal distance scenarios) also reduces the allocated percentage of this partner.

\section{Conclusions and future work}

This study developed a method to allocate benefits of costs and emissions according to contributions of the cooperating partners. A case study on VMI cooperation between Dutch supermarket chains demonstrated how the method works. The results of the case 
study showed a trade-off between costs and emissions, and multiple alternative cooperative solutions. Different emissions prices were used to determine the different solutions. In turn, emissions prices were used to allocate the monetary benefits. Most of the solutions resulted in savings for all partners. However, some partners were confronted with cost increases. Those partners have demand or location characteristics that make cooperation with the other partners non-beneficial. In practise, those partners might choose to continue individually organising their logistics, or to cooperate with partners outside the group used in the case study. The results have shown that the economic benefits of cooperation can be fairly divided, while simultaneously rewarding the effort of partners that reduce $\mathrm{CO}_{2}$ emissions and costs.

Prior to the case study, the partners were already cooperating to a limited extent. The partners arranged their procurement together and were co-owners of a shared distribution centre. Therefore, CGT methods were a logical next step in distributing benefits. In other similar cases where pre-existing forms of cooperation already exist, CGT methods are an appropriate approach for allocating cooperative benefits. Guajardo et al. (2018) studied coalition formation among cooperative agents. When there are many possible cooperative partners, it is useful to combine their techniques with CGT. Future research or other case studies could focus on situations with no pre-existing form of cooperation. In those situations, non-cooperative game theory could be used to find coalitions with a low chance of being abandoned.

In the study, emission prices between 0 and $3.95 € / \mathrm{kg}$ led to a reduction of $\mathrm{CO}_{2}$ emissions without increasing costs. All cooperative solutions resulted in a decrease of $\mathrm{CO}_{2}$ emissions compared to the current situation, even when emissions were priced at $0 € / \mathrm{kg}$. Most of the emissions prices tested were much higher than the current price. For example, $3.95 € / \mathrm{kg}$ corresponds with $3950 €$ /ton whereas in the European Trading Scheme it has varied over the last 10 years between 4 and 40 euros per ton (CBS, 2018). However, the price of $\mathrm{CO}_{2}$ emissions used in this study does not necessarily translate to an increase in costs; it mainly captures the importance a group attaches to savings attributed to $\mathrm{CO}_{2}$ emissions. It does influence the cost allocation based on the price of emissions.

The method proposed in the study can be applied to other kinds of cooperative partnerships. However, applying these methods to bigger cases can increase computation time for both the IRP model and for the Shapley value calculation. Heuristics for the IRP model and approximation methods for the Shapley value could reduce the calculation times. In this 
study, the Shapley value is used to allocate benefits based on both costs and $\mathrm{CO}_{2}$ emissions, but the proposed three-step methodology can be used with other CGT methods as well. For example, the Equal Profit Method (Frisk et al., 2010) and the methods described by Kellner and Otto (2012) could be useful for cases with more cooperating partners. Applying different CGT methods within the proposed framework can provide valuable information about the differing outcomes of cost and $\mathrm{CO}_{2}$ emissions based allocations.

\section{Acknowledgements}

This work is part of the research programme CapsLog, which is (partly) financed by the Netherlands Organisation for Scientific Research (NWO). 


\section{References}

B. Adenso-Díaz, S. Lozano, S. Garcia-Carbajal, and K. Smith-Miles. Assessing partnership savings in horizontal cooperation by planning linked deliveries. Transportation Research Part A: Policy and Practice, $66: 268-279,2014$.

A. Banasik, J. M. Bloemhof-Ruwaard, A. Kanellopoulos, G. D. H. Claassen, and J. G. A. J. van der Vorst. Multi-criteria decision making approaches for green supply chains: a review. Flexible Services and Manufacturing Journal, pages 1-31, 2016. ISSN 1936-6590.

T. Bektaş, E. Demir, and G. Laporte. Green vehicle routing. In Green Transportation Logistics, pages 243-265. Springer, 2016.

T. Bektaş and G. Laporte. The pollution-routing problem. Transportation Research Part B: Methodological, 45(8):1232-1250, 2011.

CBS. $\mathrm{CO}_{2}$-prijs emissiehandel, 2018.

L. Chen, X. Zhao, O. Tang, L. Price, S. Zhang, and W. Zhu. Supply chain collaboration for sustainability: A literature review and future research agenda. International Journal of Production Economics, 194:73-87, 2017.

L. C. Coelho, J.-F. Cordeau, and G. Laporte. Thirty years of inventory routing. Transportation Science, 48 (1):1-19, 2013.

F. Cruijssen. Framework for collaboration: A co3 position paper. Collaboration Concepts for Co-modality, 2012.

F. C. A. M. Cruijssen, M. Cools, and W. E. H. Dullaert. Horizontal cooperation in logistics: opportunities and impediments. Transportation Research Part E: Logistics and Transportation Review, 43(2):129-142, $2007 a$.

F. C. A. M. Cruijssen, W. E. H. Dullaert, and H. A. Fleuren. Horizontal cooperation in transport and logistics: a literature review. Transportation Journal, 46(3):22-39, 2007b.

F. C. A. M. Cruijssen, P. E. M. Borm, H. A. Fleuren, and H. J. M. Hamers. Supplier-initiated outsourcing: A methodology to exploit synergy in transportation. European Journal of Operational Research, 207(2): 763-774, 2010.

R. Dekker, J. M. Bloemhof, and I. Mallidis. Operations research for green logistics-an overview of aspects, issues, contributions and challenges. European Journal of Operational Research, 219(3):671-679, 2012.

M. Frisk, M. Göthe-Lundgren, K. Jörnsten, and M. Rönnqvist. Cost allocation in collaborative forest transportation. European Journal of Operational Research, 205(2):448-458, 2010.

T. Garnett. Cooking up a storm. Food, greenhouse gas emissions and our changing climate. Guildford, UK: Food Climate Research Network, Centre for Environmental Strategy, University of Surrey, 2008.

M. Guajardo. Environmental benefits of collaboration and allocation of emissions in road freight transportation. In Zeimpekis V., Aktas E., Bourlakis M., Minis I. (eds) Sustainable Freight Transport, volume 63. Springer, Cham, 2018. ISBN 978-3-319-62917-9.

M. Guajardo and M. Rönnqvist. A review on cost allocation methods in collaborative transportation. International Transactions in Operational Research, 23(3):371-392, 2016.

M. Guajardo, M. Rönnqvist, P. Flisberg, and M. Frisk. Collaborative transportation with overlapping 
coalitions. European Journal of Operational Research, 2018.

M. Hariga, R. As'ad, and A. Shamayleh. Integrated economic and environmental models for a multi stage cold supply chain under carbon tax regulation. Journal of Cleaner Production, 166:1357-1371, 2017.

J. Jonkman, A. Kanellopoulos, and J. M. Bloemhof. Designing an eco-efficient biomass-based supply chain using a multi-actor optimisation model. Journal of Cleaner Production, $\mathrm{xx}(\mathrm{xx}): \mathrm{xx}-\mathrm{xx}, 2018$.

F. Kellner and A. Otto. Allocating $\mathrm{CO}_{2}$ emissions to shipments in road freight transportation. Journal of Management Control, 22(4):451-479, 2012.

Ç. Koç, T. Bektaş, O. Jabali, and G. Laporte. The impact of depot location, fleet composition and routing on emissions in city logistics. Transportation Research Part B: Methodological, 84:81-102, 2016.

S. Lozano, P. Moreno, B. Adenso-Díaz, and E. Algaba. Cooperative game theory approach to allocating benefits of horizontal cooperation. European Journal of Operational Research, 229(2):444-452, 2013.

A. C. McKinnon. Freight transport deceleration: Its possible contribution to the decarbonisation of logistics. Transport Reviews, 36(4):418-436, 2016.

S. Naber, D. de Ree, R. Spliet, and W. van den Heuvel. Allocating $\mathrm{CO}_{2}$ emission to customers on a distribution route. Omega, 54:191-199, 2015. ISSN 0305-0483.

M. Nagarajan and G. Sošić. Game-theoretic analysis of cooperation among supply chain agents: Review and extensions. European Journal of Operational Research, 187(3):719-745, 2008.

A. H. Niknamfar and S. T. A. Niaki. Fair profit contract for a carrier collaboration framework in a green hub network under soft time-windows: Dual lexicographic max-min approach. Transportation Research Part E: Logistics and Transportation Review, 91:129-151, 2016.

O. Ö. Özener. Developing a collaborative planning framework for sustainable transportation. Mathematical Problems in Engineering, 2014, 2014.

O. Ö. Özener, Ö. Ergun, and M. Savelsbergh. Allocating cost of service to customers in inventory routing. Operations Research, 61(1):112-125, 2013.

D. Palhazi Cuervo, C. Vanovermeire, and K. Sörensen. Determining collaborative profits in coalitions formed by two partners with varying characteristics. Transportation Research Part C: Emerging Technologies, 70: 171-184, 2016.

U. Ramanathan, Y. Bentley, and G. Pang. The role of collaboration in the UK green supply chains: an exploratory study of the perspectives of suppliers, logistics and retailers. Journal of Cleaner Production, 70:231-241, 2014

C. Romero and T. Rehman. Multiple criteria analysis for agricultural decisions, volume 11. Elsevier, 2003.

M. Sanchez, L. Pradenas, J.-C. Deschamps, and V. Parada. Reducing the carbon footprint in a vehicle routing problem by pooling resources from different companies. NETNOMICS: Economic Research and Electronic Networking, 17(1):29-45, 2016.

L. S. Shapley. A value for n-person games. Contributions to the Theory of Games, 2(28):307-317, 1953.

M. Soysal, J. M. Bloemhof-Ruwaard, R. Haijema, and J. G. Van der Vorst. Modeling an inventory routing problem for perishable products with environmental considerations and demand uncertainty. International Journal of Production Economics, 164:118-133, 2015.

H. M. Stellingwerf, A. Kanellopoulos, J. G. A. J. van der Vorst, and J. M. Bloemhof. Reducing $\mathrm{CO}_{2}$ emissions in temperature-controlled road transportation using the LDVRP model. Transportation Research Part D: 
Transport and Environment, 58:80-93, 2018a.

H. M. Stellingwerf, G. Laporte, F. C. Cruijssen, A. Kanellopoulos, and J. M. Bloemhof. Quantifying the environmental and economic benefits of cooperation: A case study in temperature-controlled food logistics. Transportation Research Part D: Transport and Environment, 65:178 - 193, 2018b.

S. Tassou, G. De-Lille, and Y. Ge. Food transport refrigeration-approaches to reduce energy consumption and environmental impacts of road transport. Applied Thermal Engineering, 29(8-9):1467-1477, 2009.

S. H. Tijs and T. S. H. Driessen. Game theory and cost allocation problems. Management Science, 32(8): 1015-1028, 1986.

C. Vanovermeire and K. Sörensen. Measuring and rewarding flexibility in collaborative distribution, including two-partner coalitions. European Journal of Operational Research, 239(1):157-165, 2014.

C. Vanovermeire, K. Sörensen, A. Van Breedam, B. Vannieuwenhuyse, and S. Verstrepen. Horizontal logistics collaboration: decreasing costs through flexibility and an adequate cost allocation strategy. International Journal of Logistics Research and Applications, 17(4):339-355, 2014.

Y. Wang, X. Ma, Z. Li, Y. Liu, M. Xu, and Y. Wang. Profit distribution in collaborative multiple centers vehicle routing problem. Journal of Cleaner Production, 144:203-219, 2017.

W. Zhu, M. P. Nowak, and S. O. Erikstad. Emission allocation issues in repositioning transportation. International Journal of Sustainable Transportation, 10(4):365-375, 2016. 


\section{Appendix: Green IRP formulation}

The green IRP can be used to optimise inventory and vehicle routing decisions simultaneously. The difference with the basic IRP is that it can be used to minimise $\mathrm{CO}_{2}$ emissions but also costs. The mathematical formulation of the IRP model presented by Stellingwerf et al. (2018b) is presented below.

\section{Description of symbols}

$G=(V, A)$ denotes a graph in which $V=\{0,1, \ldots, n\}$ is the set of nodes. The CDC is located at vertex $0, V \backslash\{0\}$ is the set of DCs, and $A=\{(i, j): i, j \in V, i \neq j\}$ is the set of arcs. With every arc $(i, j)$ is associated with a non-negative distance $c_{i j} . t$ is defined as an index for the set of time periods $\{1, \ldots, T\}$, where $T$ is the length of the planning horizon. The demand at each DC $i$ in each period $t$ is given by $d_{i}^{t}$, and $C_{i}$ is the capacity of DC $i$. There is a set of identical vehicles $K=\{1, \ldots, k\}$ with capacity $Q$ and a curb (empty) weight of $Q_{0}(\mathrm{~kg})$. The speed driven on $\operatorname{arc}(i, j)$ is given by $v_{i j}$.

The following decision variables are used: $x_{i j}^{k t}$ is a binary variable equal to 1 if and only if vehicle $k$ drives from node $i$ to node $j$ in period $t ; w_{i j}^{k t}$ is the total weight carried, including the vehicle weight, from node $i$ to node $j$ by vehicle $k$ in period $t ; q_{i}^{k t}$ is the weight of the products delivered to DC $i$ by vehicle $k$ in period $t$; and $I_{i}^{t}$ is the inventory level of DC $i$ in time period $t$.

Table 9 gives an overview of all parameters used in the green IRP model. 
Table 9: Parameters used in the green IRP model.

\begin{tabular}{lll}
\hline Parameter & Unit & Definition \\
\hline$\alpha_{i j}$ & $\mathrm{~m} / \mathrm{s}^{2}$ & arc-specific constant \\
$\beta$ & $\mathrm{kg} / \mathrm{m}$ & vehicle-specific constant \\
$\Delta T$ & $\mathrm{~K}$ & difference in temperature inside an outside vehicle \\
$\eta_{m}$ & - & motive energy conversion efficiency \\
$\rho$ & $\mathrm{kg} / \mathrm{m}^{3}$ & air density \\
$\theta_{i j}$ & $\circ$ & slope of the road \\
$a$ & $\mathrm{~m} / \mathrm{s}^{2}$ & acceleration of the vehicle \\
$A$ & $\mathrm{~m}{ }^{2}$ & frontal area of the vehicle \\
$C$ & $€$ & total cost \\
$c_{i j}$ & $\mathrm{~m}$ & distance of arc $i j$ \\
$c_{0}$ & $€ / \mathrm{kg}$ & unit inventory cost CDC \\
$C_{d}$ & - & coefficient of drag \\
$c_{f}$ & $€ / \mathrm{L}$ & unit fuel cost \\
$c_{I}$ & $€ / \mathrm{kg}$ & unit inventory cost DC \\
$C_{I}$ & $€$ & inventory cost \\
$C_{i}$ & $\mathrm{~kg}$ & capacity DC $i$ \\
$C_{r}$ & - & rolling resistance \\
$C_{t}$ & $€$ & transportation cost \\
$c_{w}$ & $€ / \mathrm{s}$ & unit wage cost \\
$d_{i}^{t}$ & - & demand node $i$ in period $t$ \\
$E$ & $\mathrm{~kg} \mathrm{CO} 2$ & total emissions for transportation \\
$e_{f}$ & $\mathrm{~kg} / \mathrm{L}$ & fuel to CO ${ }_{2}$ emissions factor \\
$f$ & $\mathrm{~L}$ & fuel use for ambient transport \\
$g$ & $\mathrm{~m} / \mathrm{s}^{2}$ & gravitation constant \\
$m$ & & number of vehicles \\
$P_{i j}$ & $\mathrm{kWh}$ & motive power on arc $i j$ \\
$P_{f}$ & $\mathrm{kWh} / \mathrm{L}$ & energy content of the fuel \\
$Q$ & $\mathrm{~kg}$ & vehicle capacity \\
$Q_{0}$ & $\mathrm{~kg}$ & curb weight \\
$s$ & $\mathrm{~s}$ & service time at each stop \\
$v_{i j}$ & $\mathrm{~m} / \mathrm{s}$ & speed driven on arc $i j$ \\
\hline & &
\end{tabular}




\section{Objective functions}

The IRP formulated by Stellingwerf et al. (2018b) uses two objective functions: to minimise $\mathrm{CO}_{2}$ emissions from transportation and to minimise costs from transportation and inventory.

Transportation $\mathrm{CO}_{2}$ emissions $E$ can be approximated as

$$
\begin{aligned}
E & =f e_{f} \\
& \left.=\left(\sum_{i \in V} \sum_{j \in V} \sum_{k \in K} \sum_{t \in T} \alpha w_{i j}^{k t} c_{i j}+\sum_{i \in V} \sum_{j \in V} \sum_{k \in K} \sum_{t \in T} \beta c_{i j} x_{i j}^{k t} v_{i j}^{2}\right) \frac{1}{3.6 \times 10^{6} P_{f} \eta_{m}}\right) e_{f},
\end{aligned}
$$

where the first two terms of the equation are used to calculate the motive power

requirement $(\mathrm{kWh})$, which is converted to fuel use by dividing the power by $3.6 \times 10^{6}$ to convert $\mathrm{J}$ to $\mathrm{kWh}$, by the chemical to motive energy conversion efficiency $\left(\eta_{m}\right)$, and by the energy content of the fuel $\left(P_{f}\right)$. Then the fuel use is converted to $\mathrm{CO}_{2}$ emissions by using the $\mathrm{CO}_{2}$ emissions factor $\left(e_{f}\right.$, in $\left.\mathrm{kg} / \mathrm{L}\right)$.

Other terms used are $\alpha_{i j}$, which is the arc-specific constant; $\beta$, which is the vehiclespecific constant; $c_{i j}$, which is the distance from node $i$ to node $j(\mathrm{~m})$; and $v_{i j}$, which is the speed $(\mathrm{m} / \mathrm{s})$ with which arc $i j$ is traversed $(\mathrm{m} / \mathrm{s})$.

Total costs $C$ can be approximated as

$$
\begin{aligned}
C & =C_{t}+C_{I}=C_{w}+C_{f}+C_{I} \\
& =\sum_{i \in V} \sum_{j \in V} \sum_{m \in M} \sum_{t \in T} \frac{c_{w} c_{i j} x_{i j}^{k t}}{v_{i j}}+\sum_{i \in V^{\prime}} \sum_{j \in V} \sum_{k \in K} \sum_{t \in T} c_{w} x_{i j}^{k t} s \\
& +\sum_{i \in V} \sum_{j \in V} \sum_{k \in K} \sum_{t \in T} \alpha w_{i j}^{k t} c_{i j} \sum_{i \in V} \sum_{j \in V} \sum_{k \in K} \sum_{t \in T} \beta c_{i j} x_{i j}^{k t} v_{i j}^{2} \frac{1}{3.6 \times 10^{6} P_{f} \eta_{m}} c_{f} \\
& +\sum_{i \in V} \sum_{t \in T} I_{i}^{t} c_{I},
\end{aligned}
$$

where $C_{t}$ refers to the transportation cost $(€), C_{I}$ refers to the inventory cost $(€), C_{w}$ refers to the total wage cost $(€), C_{w}$ refers to the total fuel cost $(€), c_{f}$ is the unit fuel cost $(€ / \mathrm{L})$, and $c_{w}$ is the unit wage cost $(€ / \mathrm{s}), c_{I}$ are the unit inventory $\operatorname{cost}(€ / \mathrm{kg} /$ day $)$. 


\section{Constraints}

The IRP constraints can be subdivided in three main types: (i) inventory constraints: they impose minimum and maximum levels of the inventory of the depot and the destinations in each period considering an initial inventory level; (ii) vehicle routing constraints: they impose that a delivery can be made to a location only if it is visited by a vehicle, and that a vehicle cannot visit the same location multiple times in the same time period, they restrict the number of vehicles used per day, and they define vehicle capacity; (iii) flow constraints: these define how the load of the vehicle changes after visiting a location, eliminate sub tours, and define impossible arcs. The constraints are formulated as follows:

$$
\begin{aligned}
& I_{0}^{t}=I_{0}^{t-1}-\sum_{i \in V^{\prime}} \sum_{k \in K} q_{i}^{k t} \quad t \in\{2, \ldots, T\} \\
& I_{0}^{1}=\sum_{i \in V^{\prime}} \sum_{t \in T} d_{i}^{t} \\
& I_{i}^{t}=I_{i}^{t-1}+\sum_{k \in K} q_{i}^{k t}-d_{i}^{t} \quad i \in V^{\prime}, t \in T \\
& I_{i}^{1}=0 \quad i \in V^{\prime} \\
& I_{i}^{t} \geq 0 \quad i \in V^{\prime}, t \in T \\
& I_{i}^{t} \leq C_{i} \quad i \in V^{\prime}, t \in T \\
& \sum_{k \in K} q_{i}^{k t} \leq C_{i}-I_{i}^{t-1} \quad i \in V^{\prime}, t \in\{2, \ldots, T\} \\
& q_{i}^{k t} \leq C_{i} \sum_{j \in V} x_{i j}^{k t} \quad i \in V^{\prime}, k \in K, t \in T \\
& w_{i j}^{k t} \leq\left(Q+Q_{0}\right) x_{i j}^{k t} \quad i \in V, j \in V, k \in K, t \in T \\
& w_{i j}^{k t} \geq Q_{0} x_{i j}^{k t} \quad i \in V, j \in V, k \in K, t \in T \\
& \sum_{j \in V} x_{i j}^{k t} \leq n \sum_{j \in V^{\prime}} x_{0 j}^{k t} \quad i \in V, k \in K, t \in T \\
& \sum_{k \in K} \sum_{i \in V} x_{i j}^{k t} \leq 1 \quad j \in V^{\prime}, t \in T \\
& \sum_{j \in V^{\prime}} x_{0 j}^{k t} \leq 1 \quad k \in K, t \in T \\
& x_{i j}^{k t}+x_{j i}^{k t} \leq 1 \quad i \in V^{\prime}, j \in V^{\prime}, k \in K, t \in T \\
& x_{i i}^{k t}=0 \quad i \in V, k \in K, t \in T
\end{aligned}
$$




$$
\begin{array}{rlrl}
\sum_{j \in V} x_{i j}^{k t} & =\sum_{j \in V} x_{j i}^{k t} i \in V, k \in K, t \in T \\
\sum_{i \in V \mid i \neq j} w_{i j}^{k t}-\sum_{i \in V \mid i \neq j} w_{j i}^{k t} & =q_{i}^{k t} \quad j \in V^{\prime}, k \in K, t \in T \\
w_{i j}^{k t} & \geq 0 & & i \in V, j \in V, k \in K, t \in T \\
q_{i}^{k t} & \geq 0 & i \in V^{\prime}, k \in K, t \in T \\
I_{i}^{t} \geq 0 & i \in V, t \in T \\
x_{i j}^{k t} & \in\{0,1\} & i \in V, j \in V, k \in K, t \in T .
\end{array}
$$

Constraints (6)-(12) are inventory related constraints: constraints (6)-(7) define the inventory at the CDC, while constraints (8)-(11) define the inventories at the DCs, and constraints (12) are the maximum level inventory policy constraints. Constraints (13)-(20) are vehicle related constraints: Constraints (13) state that no delivery can be made at DC $i$ in period $t$ when there is no vehicle visiting that node in that period, constraints (14) and (15) are the vehicle capacity constraints, constraints (16) restrict the number of vehicles used per day, constraints (17) restrict the number of visits to each DC to at most one per day, constraints (18) state that at most one vehicle per day visits each location, constraints (19) state that a vehicle leaves from the same DC as the one it entered, and constraints (20) eliminate impossible arcs. Constraints (21)-(22) are flow related constraints: constraints (21) are the flow conservation equations, and constraints (22) eliminate sub tours. Constraints (23)-(26) are nonnegativity and binary constraints: constraints (23)-(25) are nonnegativity constraints, while constraints (26) are binary constraints.

To run the IRP model, the values given in Table 10 are used. 
Table 10: Values used to run the green IRP model.

\begin{tabular}{lrll}
\hline Symbol & Value & Unit & Source \\
\hline$\alpha_{i j}$ & 0.0981 & $\mathrm{~m} / \mathrm{s}^{2}$ & Stellingwerf et al. (2018a) \\
$\beta$ & 3.013 & $\mathrm{~kg} / \mathrm{m}$ & Stellingwerf et al. (2018a) \\
$\eta_{m}$ & 0.3 & - & Bektaş and Laporte (2011) \\
$\rho$ & 1.2041 & $\mathrm{~kg} / \mathrm{m}^{3}$ & Bektaş and Laporte (2011) \\
$A$ & 7.15 & $\mathrm{~m}^{2}$ & Stellingwerf et al. (2018a) \\
$c_{0}$ & 0.001 & $€ / \mathrm{kg}$ & Soysal et al. (2015) \\
$C_{d}$ & 0.7 & - & Bektaş and Laporte (2011) \\
$c_{f}$ & 1.4 & $€ / \mathrm{L}$ & Bektaş et al. (2016) \\
$c_{I}$ & 0.01 & $€ / \mathrm{kg}$ & Soysal et al. (2015) \\
$C_{r}$ & 0.01 & - & Bektaş and Laporte (2011) \\
$c_{w}$ & 0.0022 & $€ / \mathrm{s}$ & Bektaş et al. (2016), Stellingwerf et al. (2018a) \\
$e_{f}$ & 2.668 & $\mathrm{~kg} / \mathrm{L}$ & Tassou et al. (2009) \\
$g$ & 9.81 & $\mathrm{~m} / \mathrm{s}^{2}$ & \\
$m$ & 3 & - & \\
$P_{f}$ & 8.8 & $\mathrm{kWh} / \mathrm{L}$ & Bektaş and Laporte (2011) \\
$Q$ & 12500 & $\mathrm{~kg}$ & Koç et al. (2016) \\
$Q_{0}$ & 5500 & $\mathrm{~kg}$ & Koç et al. (2016) \\
$s$ & 900 & $\mathrm{~s}$ & \\
$v_{i j}$ & 20 & $\mathrm{~m} / \mathrm{s}$ & Tassou et al. (2009) \\
\hline
\end{tabular}

